\title{
O PODER NORMATIVO DO CONSELHO FEDERAL DE MEDICINA E O DIREITO CONSTITUCIONAL À SAÚDE ${ }^{(*)}$
}

THE RULEMAKING COMPETENCE OF THE MEDICINE FEDERAL BOARD AND THE CONSTITUTIONAL RIGHTS DO HEALTH AID

Sergio Domingos Pittelli(**)

\section{RESUMO}

Os conselhos profissionais no Brasil constituem autarquias e, portanto, são órgãos da Administração indireta. Não sendo titulares do poder de legislar, sua ação, entretanto, se reveste da agilidade própria da competência normativa da Administração. O Conselho Federal de Medicina, que é uma autarquia, tem-se despido, nos últimos anos, do ranço corporativista que costuma caracterizar os órgãos de classe, adotando feições de órgão da sociedade civil, o que the confere uma situação sui generis. Por tais motivos, é interessante examinar a produção normativa e a atividade fiscalizadora deste órgão sob o ponto de vista da garantia do direito constitucional à saúde. Foram examinadas e classificadas 106 resoluções normativas como forma de propor uma tipologia que permita um primeiro e preliminar entendimento de como esta competência normativa e fiscalizatória pode atuar e que deverá também se prestar a futuras avaliações sob outras formas ou modelos metodológicos.

\section{Palavra-chave}

Poder regulamentar, Princípio da legalidade, Interesse público, Vigilância sanitária.

(*) Este trabalho contou com a valiosíssima orientação do Professor Doutor Sebastião Botto de Sarros Tojal, nosso orientador na monografia de conclusão de curso, a quem somos profundamente reconhecidos e gratos.

$\left.{ }^{\star *}\right)$ Médico neurologista e administrador em saúde, advogado especializado em direito sanitário. 


\section{ABSTRACT}

The professional boards in Brazil are autarkies and so, they are selfadministrator public agencies. They have no legal competence to legislate, but, otherwise, their rulemaking process is very simple, just like the governmental agencies' one. The Medicine Federal Board is an autarky which has lost, in the last years, the corporative features, usually present in this kind of organization, and has adopted the characteristics of the Civic Community, what ascribes it a sui generis condition. For all those reasons, it is interesting to study its rulemaking production as well as its control activities from a point of view of the constitutional rights to health aid. 106 rules enacted by the Medicine Federal Board were examined and classified as a mean to create a taxonomy that permits an initial and preliminary comprehension of how its rulemaking legal competence works, as well as to serve to future appreciations under other methodological models.

\section{Keywords}

Regulatory power, Rule of law, Public interest, Sanitary surveillance.

\section{INTRODUÇÃO}

O presente trabalho pretende propor um modelo de avaliação do poder normativo e fiscalizador do Conselho Federal de Medicina (CFM) do ponto de vista da efetivação do direito constitucional à saúde.

O Conselho Federal e os Conselhos Regionais de Medicina são autarquias criadas pela Lei n. 3.268, de 30 de setembro de 1957, com competência para supervisionar a ética profissional e fiscalizar o exercício da profissão.

Embora auto-administráveis, as autarquias não são autônomas, ou seja, não se constituem em pessoas públicas jurídicas e, portanto, não têm o poder de legislar. Não obstante, por serem agentes da descentralização do Estado, têm a outorga real e efetiva de poderes(11), possuindo vontade própria e certa independência com relação à vontade do centro(11). Desses enunciados, exsurge claro o conceito de que, embora ínsita à sua natureza a impossibilidade de legislar, as autarquias exercem, na qualidade de entidades da Administração, o poder normativo do Estado, com as características gerais a ele atribuídas: estabelecer normas de alcance limitado ao âmbito de atuação do órgão expedidor, desde que não contrariem a lei nem imponham obrigações, proibições e penalidades que nela não estejam previstas(13). As Resoluções Normativas do Conselho Federal de Medicina são manifestação deste poder normativo afeto às autarquias. 
O Estado Liberal, surgido do lluminismo, trouxe em seu bojo a consagração dos direitos civis, chamados direitos humanos de primeira geração. A estes seguiram-se historicamente, a partir de fins do século XIX, já sob a égide do Estado Social, os chamados direitos sociais, também denominados direitos humanos de segunda geração. Na Constituição Federal brasileira, os direitos sociais acham-se listados no art. 6‥ A saúde, compreendida entre eles, é tratada de modo específico nos arts. 196 a 200.

$O$ acolhimento constitucional dos direitos sociais e conseqüente consignação a eles do atributo de direitos humanos implicou novas questões teóricas e práticas para o Direito, uma vez que o sistema jurídico tradicional, próprio do Estado burguês - calcado no conceito de direito subjetivo violado e aparelhado para dirimir conflitos intersubjetivos -, mostrou ser instrumento inadequado para a garantia e a concretização dessas novas demandas(10). Nessa nova conjuntura, a simples declaração de direitos não é satisfatória(6) e, segundo Dallari(7), "a experiência já demonstrou que a simples afirmação, ainda que constitucional, do direito à saúde não tem gerado na prática a sua aplicabilidade".

Podemos concluir afirmando que essa nova realidade atribuiu ao Direito a qualidade de instrumento de atuação de políticas públicas que visam a concretizar os direitos constitucionalmente declarados.

Os modos pelos quais o Direito se presta a cumprir esta nova função são variados e complexos, distribuindo-se pelos planos constitucional e infra-constitucional.

No plano constitucional, além da declaração dos direitos (por si só insuficiente, como já vimós(7)), opera também mediante a forma como é organizado o Estado e as competências para legislar e executar as várias políticas sociais. Dallari(7) mostra a importância da distribuição de competência legislativa entre União, Estados e municípios (art. 23, II, da CF) e a atribuição aos municípios da competência de "prestar ... serviços de atendimento à saúde da população" (art. 30, VII, da CF).

No plano do direito substancial, as novas concepções de direitos difusos e coletivos e ainda de direitos individuais homogêneos, e, no plano do direito processual, as correspondentes ações coletivas e a criação de novas titularidades para o direito de ação (corpos intermediários) ou ampliação das hipóteses de legitimação para as já existentes (Ministério Público) são as mudanças geradas no seio deste Direito, que se aparelha para instrumentalizar as políticas públicas estatais na área dos direitos sociais.

No plano do Direito Público, em todas as suas vertentes, incluído o Direito Administrativo, operam-se modificações num Estado que se apareIha para operar políticas públicas e intervir no campo econômico ou ainda integrar blocos supranacionais. Segundo Gordillo(9), a crescente interven- 
ção do Estado no processo social não só não implica o seu agigantamento, como promove alterações nas relações entre a "sociedade política" e a Administração, aumentando o caráter participativo daquela em detrimento do "império de autoridade" e da "executoriedade unilateral" desta última. Nesse Estado que intervém no processo social sem perder sua qualidade de Estado democrático de direito, aumenta a força do processo judiciário como instrumento de luta política e as formas de direito público a ela associadas adquirem caráter progressivamente processualístico e instrumental. $O$ Direito Administrativo clássico, nascido do Estado Liberal, é aparelhado para estruturar órgãos, poderes e pessoal da Administração; trata-se de um Direito Administrativo "estático". O controle constitucional do poder econômico e das políticas públicas do Estado Social requer um Direito Administrativo dinâmico, "processual", que se presta à consecução dos direitos sociais.

Finalmente, no plano do Direito Processual, Dinamarco(8) mostra que, modernamente, não há mais lugar no estudo deste ramo do Direito para "investigações conceituais destituídas de endereçamento teleológico" e conclui que "Assoma, nesse contexto, o chamado aspecto ético do Processo, a sua conotação deontológica", significando com isso a negação da natureza e objetivo puramente técnicos do sistema processual em favor da "afirmação de sua permeabilidade aos valores tutelados na ordem político-constitucional e jurídico-material (os quais buscam efetividade através dele) e reconhecimento de sua inserção no universo axiológico da sociedade a que se destina".

Segundo Tojal(18), as características das modernas constituições têm influenciado todo o Direito. Transcrevendo Gunther Teubner, esclarece que o "Direito material próprio da moderna era industrial ... não se limita a satisfazer os imperativos de resolução dos conflitos impostos pelo funcionamento de uma sociedade de mercado, mas serve também a imperativos políticos de intervenção e direção próprios do moderno Estado Social: quer dizer, o Direito é instrumentalizado em função dos objetivos e finalidades do sistema político, ..." (grifos nossos), para logo em seguida afirmar, agora com palavras próprias: "Especialmente no campo da saúde pública, é absolutamente imperativo reconhecer que sua proteção se faz exata e precisamente pela compreensão de que as normas típicas do que já se definiu como Direito Sanitário não se conformam aos modelos clássicos de um direito concebido à luz de paradigmas estatutários, informados por princípios como certeza e segurança jurídicas, já que é inerente a esse processo de rematerialização da racionalidade legal o particularismo, a legitimidade determinada pela observância de critérios fundados em uma ética de conviç̧ão, a partir da qual os fins acabam definindo os meios necessários para sua consecução, tudo perfeitamente em consonância com os novos desígnios constitucionais já referidos" (grifo nosso).

Concluindo, pretendemos salientar que não apenas o Direito Processual em seu sentido estrito, como demonstrou Dinamarco, mas tam- 
bém o Direito Material sob a égide do Estado moderno (Direito Administrativo, incluído aí o Direito Sanitário), como demonstram os autores acima citados, assumem características teleológicas e orientam-se por princípios axiológicos, elementos essenciais de sua instrumentalidade. É nesse sentido que se aplica e que efetivamente temos aplicado o qualificativo "processualístico" ao Direito Sanitário. O Direito Sanitário deve constituir-se, portanto, em forma "processualizada" do Direito Público, que permita operacionalizar políticas de tutelas do direito à saúde.

Retomando à finalidade primeira deste artigo, lembramos que o propósito do presente trabalho é apresentar um modelo que permita verificar, ainda que de forma preliminar, se e em que medida o poder fiscalizador e as Resoluções Normativas emanadas do CFM se prestam a subsidiar essa vocação processualizante e instrumental do Direito Sanitário, colaborando na consecução das políticas públicas do Estado na efetivação do direito social à saúde.

A nosso ver, há mais de um motivo a justificar o interesse de particularizar este estudo à instância e ao plano a que pretendemos neste texto. Numa primeira ordem de idéias, lembraremos que, por características intrínsecas, a classe médica ocupa posição sui generis no conjunto das profissões da área, com grande capacidade de influir em elementos estruturais do sistema de saúde. É razoável supor que o fato de a atividade normativa e fiscalizadora dos Conselhos de Medicina se exercer sobre essa classe pode ser de grande repercussão na conformação de todo o sistema. Um segundo motivo é dado pelas conhecidas características do processo de produção normativa não legislativa, tido como simples e "ágil" quando comparado ao processo legislativo, motivo ainda reforçado pelo nosso entendimento pessoal de que essa diferença também se faz presente quando comparamos a Administração direta com a indireta, favorecendo esta última. Essa circunstância, aliada à eventual maior sensibilidade das autarquias corporativas aos reclamos e pressões da sociedade civil, segundo pretendemos expor a seguir, torna particularmente interessante conhecer 0 comportamento e as características da atividade normativa desse tipo de ente. O terceiro motivo, a nosso ver o mais importante, requer alguma digressão teórica prévia.

Di Pietro(14), ao classificar as autarquias em funcionais e corporativas, nos ensina que estas últimas são constituídas precipuamente por sujeitos unidos para a consecução de um fim de interesse público, mas que diz respeito aos próprios associados e ainda, referindo-se à primeira "... o elemento essencial é a existência de determinados membros que se associam para atingir a certos fins que a eles mesmos beneficiam; ..." (destacamos).

Por óbvio que seja o fato de a autora não ter usado os termos por nós grifados com a estrita conotação que pretendemos consignar a seguir, a experiência mostra efetivamente que os conselhos profissionais, de modo 
geral, trazem, de origem, forte traço de defesa de interesses próprios e exclusivos da classe que representam. Após recrudescimento dessa característica nos anos dos governos militares, a redemocratização trouxe, durante a década de 1980, tendência à substituição de grupos conservadores por grupos progressistas no comando dos órgãos de classe. A essa mudança correspondeu um novo discurso de alinhamento aos princípios que, já delineados, viriam a informar a Constituição Federal no final da década, e, a nosso ver, dar maior sensibilidade aos reclamos e pressões da sociedade civil.

Seguindo essa linha de pensamento e ainda que a guisa de hipótese, admitimos que os Conselhos profissionais, especialmente na área da medicina, tenderam, nos últimos anos, a adotar as características do que Putnam(15) denomina "civic engagement". Esse autor americano contrapõe o conceito de "virtude cívica" de Machiavel e outros, os quais chama de "humanistas republicanos" ao conceito de liberalismo de Hobbes, Locke e outros. Enquanto os "republicanos", enfatizavam a comunidade e as obrigações relativas à cidadania e vida em comunidade, os liberais enfatizavam o liberalismo e os direitos individuais. Dos primeiros, remontando a Tocqueville, nasceu o conceito de "comunidade cívica" caracterizada, nas palavras de Putnam, "by active participation in public affairs", ou, dito de outra forma, pela grande propensão em formar organizações civis e políticas e com elas participar da vida da comunidade e dos assuntos públicos. Embora tanto os clássicos quanto o próprio Putnam, em seus estudos se refiram a comunidades, entendemos que o conceito seja plenamente aplicável a órgãos supracomunitários e ainda representativos de classes profissionais, tais como a organização que ora estudamos, desde que esta tenha conseguido se livrar de seu ranço "oficialista" e corporativista como efetivamente parece ter acontecido. Assim entendido, as ações do Conselho Federal de Medicina podem ser consideradas provenientes de um órgão da sociedade civil, chamando para esta, em contraposição ao Estado, parcela importante da responsabilidade de gerir a vida da nação na área de sua competência. Daí, a nosso ver, o talvez mais importante motivo para levarmos a cabo o presente estudo.

Concluindo esta introdução, diremos que, ao estudo centrado nos níveis constitucional e infraconstitucional (e, neste último, tanto no que se refere ao direito substancial quanto ao processual), em que se operam as mudanças vocacionadas a aparelhar o Direito como instrumento de políticas públicas do Estado, alinhamos um "terceiro nivel", constituído por normas não legislativas, emanadas de um ente da Administração indireta com as características acima discutidas, das quais se ressalta como a mais importante, embora não única, a de que incorpora a natureza de elemento da Sociedade Civil mais do que propriamente órgão do Estado. Pretendemos, assim, juntar mais um pequeno elemento no imenso edifício que constitui esta apaixonante área de estudos, que poderá, eventualmente, trazer contribuições pertinentes e abrir um novo campo de interesse dentro do capítulo do Direito Sanitário. 


\section{MATERIAL}

Foram analisadas 106 das 107 Resoluções Normativas do Conselho Federal de Medicina, e classificadas segundo critérios que serão explicados a seguir. O conjunto cobre o período de 1965 a dezembro de 1999. A Resolução Normativa n. 1246, de 1988, tem natureza sui generis quando comparada às demais, por se constituir na instituidora do Código de Ética Médica vigente e, a nosso ver, pela sua natureza e complexidade, não se presta ao tipo de análise a que nos propusemos.

\section{CONSIDERAÇÕES METODOLÓGICAS}

A análise que pretendemos levar a efeito se refere a aspectos de eficácia das normas e por esse motivo cumpre, previamente, ater-nos em breve digressão teórica sobre este conceito.

Segundo Bobbio(1), a norma eficaz é aquela que é obedecida pelos destinatários ou, no caso negativo, imposta coercitivamente. De outro modo, ensina-nos Reale(16) que "O Direito autêntico não é apenas declarado mas reconhecido, é vivido pela sociedade, como algo que se incorpora e se integra na sua maneira de conduzir-se". $E$ aduz, a seguir: "A regra de direito deve, por conseguinte, ser formalmente válida e socialmente eficaz' (grifado no original). Dos ensinamentos dos dois mestres depreendem-se os dois grandes componentes da eficácia: a validade formal, que na verdade é mais um pressuposto, e a eficácia social, ou seja, a efetiva obediência por parte dos destinatários, esta sim, a verdaderia medida da eficácia, entendido este termo em sentido estrito. Em termos de direitos sociais, por exemplo, diremos que a norma eficaz seria aquela que promovesse a concreta e real fruição dos direitos por ela regulados, por parte dos beneficiários, mesmo que à custa da imposição coercitiva de condutas daqueles que, responsáveis pela prestaçẳo, de alguma forma dela se eximissem.

Por outro lado, e retornando a Bobbio(1), devemos registrar que a pesquisa sobre a eficácia das normas é de cunho essencialmente histórico - sociológico. Na mesma linha de pensamento, detalhando um pouco mais a análise, Campilongo(5) afirma que "A eficácia jurídica é tema, por excelência e tradição, atinente à sociologia jurídica. $O$ enfoque sociojurídico, por sua vez, pode adotar tanto uma perspectiva empírica (normalmente atribuída à sociologia jurídica norte-americana) quanto uma postura teóricoespeculativa (segundo alguns, mais próxima da sociologia jurídica européia)". É o nosso entendimento que estas duas perspectivas são, na verdade, complementares, uma vez que toda avaliação empírica de qualquer fenômeno pressupõe um momento anterior de descrição e classificação dos 
elementos do objeto em estudo (atitude que se enquadra na perspectiva teórico-especulativa, segundo nosso entendimento), à qual se seguirão procedimentos no sentido de testar as hipóteses levantadas no momento da classificação - Campana(3) e Moles(12).

A natureza e alcance do presente trabalho não são de molde a comportar estudos de natureza empírica sobre eventuais efeitos concretos das Resoluções Normativas do CFM sobre a realidade fática relativa ao atendimento à saúde no país. Preferimos, num primeiro momento e em face das proporções que um tal estudo tomaria, realizar uma análise geral do conjunto de normas, procurando identificar fatores gerais e comuns a grupos delas que pudessem, em tese, integrar o caráter "processualístico" do direito sanitário a que nos referimos na introdução a este texto e conferir-lhes, assim, um caráter ao menos teoricamente eficaz. Esse tipo de análise, global e teórica, serviria como uma primeira avaliação a sugerir direrizes de pesquisas ulte-riores, mais específicas e enventualmente empíricas. O que pretendemos, portanto, num primeiro momento, é realizar um estudo classificatório ou mesmo taxonômico das normas emanadas pelo CFM (criando, tanto quanto possível, uma tipologia); agrupando-as segundo critérios que, inicialmente, parecem arbitrários (Moles, op. cit., p. 132), deverão, num segundo momento, mostrar-se pertinentes para a finalidade última que será avaliar a eficácia das normas de um ponto de vista estritamente empírico. Para os fins desta discussão, consideraremos como possuidoras de eficácia em tese as normas nas quais se puder identificar como beneficiária direta de seus comandos a própria população. Decorre desta consideração que efeitos "meramente reflexos" não integram esta propriedade. Também como corolário, e em caráter preliminar, podemos afirmar que o benefício à população poderá advir do valor da norma para a restauração de um direito violado ou, ainda, pelo uso por parte de órgãos estatais na fiscalização das atividades inerentes ao setor saúde.

Feitas essas digressões, discutiremos o modelo de classificação das normas, reportando-nos aos elementos ou critérios que, numa visão preliminar, julgamos pertinentes para agrupá-las.

Isto posto, propomos, como um primeiro critério de classificação, a distinção entre normas de caráter estritamente administrativo, que se referem a aspectos organizacionais ou de funcionamento interno dos ConseIhos e normas que constituem prescrições de variada natureza, a serem observadas por destinatários externos aos próprios Conselhos, que são, naturalmente, médicos e pessoas jurídicas submetidas à fiscalização.

Cada um desses critérios, por sua vez, admite um segundo nível de discriminação.

Assim, para o primeiro, cumpre distinguir as normas administrativas "gerais" ou "meramente" administrativas daquelas que organizam o siste- 
ma fiscalizatório dos Conselhos, enquanto, para o segundo, a distinção se refere à natureza técnica ou não técnica da matéria regulada pela norma, o qualificativo técnico aqui sendo entendido em caráter estritamente médico.

Feita a análise das normas, propomo-nos então a avaliar a eficácia em tese de cada grupo, verificando, nesse primeiro momento, se a tipologia assim formada se mostra pertinente para a aferição da eficácia nos termos acima expostos.

Antes de passarmos à descrição dos grupos, entretanto, faz-se necessária uma última explicação a respeito dos critérios de classificação. 0 estudo individualizado das normas revelou-nos serem pertinentes algumas características comuns a certos grupos de resoluções que não integravam o modelo previamente concebido para classificá-las. A natureza de tais características afasta completamente qualquer possibilidade de sistematização prévia, motivo pelo qual não foram antevistas. Não podendo, assim, teorizar sobre elas, tampouco cabe citá-las de antemão, motivo pelo qual serão descritas e discutidas à medida que aparecerem como elementos definidores de subgrupos de normas. Num certo sentido, esta forma de apresentá-las reproduzirá as mesmas etapas de cognição por que passamos até conhecer de sua importância. Registre-se que esta circunstância não é estranha à atividade classificatória (Moles, op. cit., p. 132).

Concluímos, portanto, registrando que o modelo de classificação das normas comporta dois grupos de critérios: 1. um grupo constituído por quatro critérios previamente estabelecidos, aplicados sistematicamente a todas as resoluções e que chamaremos, para facilitar a exposição, de "critérios sistemáticos"; 2. algumas características próprias e exclusivas de conjuntos específicos de normas que por algum elemento de sua natureza teve a força de uni-las e defini-las como um grupo, independentemente da incidência dos demais critérios; denominá-las-emos de "características próprias" ou "exclusivas".

Como última observação, registraremos que não levamos em conta, no presente estudo, aspectos da redação dos dispositivos ou aspectos outros que possam tornar a norma pouco aplicável (e, em tese, pouco ou nada eficaz), mas que possam ser corrigidos por nova redação, uma vez que a análise individual das resoluções sob este aspecto também foge ao escopo deste trabalho, não obstante entendermos ser de grande interesse prático e teórico.

Feitas estas considerações, apresentaremos sucintamente os grupos de normas, discutindo-os no tópico seguinte. Foram identificados sete grupos, nomeados seqüencialmente.

O grupo A é constituido pelas normas "meramente" administrativas ou organizacionais. 
Os grupos $B, C, D, E$ e $F$ têm em comum o fato de conter normas com proposições prescritivas(2) direcionadas aos destinatários naturais dos Conselhos de Medicina. Os grupos B, C e D distinguem-se por possuir, ainda, cada um, uma característica própria, não sistemática, definidora do grupo. O objeto das resoluções dos grupos B e C, por sua vez, é indubitavelmente de natureza não técnica; o mesmo se pode dizer do grupo $D$, mas esta afirmação merece comentários. Os grupos $E$ e $F$ compõem-se de normas que prescrevem formas de procedimentos dirigidas diretamente aos médicos, sem nenhuma característica própria que os defina, no mesmo sentido que ocorre para os grupos $B, C$ e $D$, diferenciando-se apenas entre si por serem os objetos das primeiras de natureza não técnica, contrariamente às segundas.

O grupo G é constituído por normas que, não obstante serem de natureza fundamentalmente administrativa, se prestam a organizar e operacionalizar o sistema fiscalizatório dos Conselhos.

A Tabela 1 mostra, sob forma de quadro sinóptico, a classificação dos grupos segundo o conjunto de critérios.

\section{DISCUSSÃO}

O grupo A, conforme já referido, é constituido por resoluções que tratam de assuntos meramente organizacionais ou de rotina de funcionamento dos Conselhos, e, como tais, não se prestam a qualquer medida dirigida diretamente aos usuários, não apresentando, portanto, maiores interesses para os propósitos deste estudo.

O grupo B é constituído por normas que contêm prescrições de procedimentos não técnicos que regulam direitos afetos diretamente ao médico, em aspectos do exercício da profissão. Esse grupo manifesta, ainda, a nosso ver, característica própria constituída por concepção que se afeiçoa a um modelo de medicina entendida como profissão liberal, calcada em práticas individuais e relacionamento médico-paciente baseado na livre escoIha. Tal concepção se encontra ultrapassada pelas condições que regem a remuneração e o emprego do médico na atualidade, caracterizadas pelo assalariamento e pela interveniência de empresas custeadoras de assistência à saúde, circunstâncias que tornaram a remuneração médica mera questão de mercado, simplesmente não controlável por normas da natureza das que tratamos neste texto. Some-se a tais considerandos a universalização do direito à saúde instaurada pela Constituição de 1988, com a conseqüente necessidade de promover 0 atendimento a toda a massa de população, fator que também exige mecanismos de remuneração e relação médico-paciente que escapam às formas tradicionais. Por todo o exposto, 
entendemos que este conjunto de normas não se presta à defesa de direitos dos usuários, não possuindo condição de eficácia, em nenhum dos sentidos propostos.

O grupo $C$ é constituído por normas prescritivas que regulam matéria não técnica. O conjunto define-se pela presença marcante e ubíqua de uma característica: apresentar prescrições robusta e exclusivamente genéricas de formas de comportamento a serem observadas pelos médicos ou Conselhos Regionais. Além da generalidade das disposições, contribui para a inocuidade deste grupo de resoluções o fato de que certas recomendações ou mesmo determinações se fazem com objetos que, de outro modo, são a própria finalidade da existência dos Conselhos (Resolução n. 476) ou decorrência natural da lei e/ou princípios do Direito (Resoluções n. 663, art. 19, e 672 , arts. $1^{\circ}$ e $\left.3^{\circ}\right)$. Concluindo, podemos registrar que tais normas, a exemplo do grupo anteriormente estudado, também não se revestem de eficácia no sentido entendido neste trabalho.

Iniciaremos a análise do Grupo $D$ enunciando sua característica própria, "não sistemática": nelas o CFM atribui a qualidade de "ato médico" a determinados procedimentos e, assim, o fazendo, garante ao médico a exclusividade para realizá-los. Esta característica confere ao conjunto de normas uma situação 'sui generis: na verdade, os destinatários dessas normas são os profissionais das demais profissões de saúde, pois é a eles que incumbe se abster de praticar "atos médicos". Embora não pretendamos nos deter nesse ponto, entendemos que não são elementos de natureza exclusivamente técnica que regem tais decisões. Aliás, a fronteira entre profissões da área da saúde dá oportunidade a disputas às quais elementos corporativos e de interesse de mercado não são alheios, se é que não predominam na maior parte das vezes. Tais disputas (as quais, diga-se de passagem, não têm necessariamente a medicina como um dos pólos) dizem muito pouco, se é que dizem algo, ao interesse do usuário. Entendemos, portanto, que estas resoluções não satisfazem as condições de eficácia nos termos propostos neste trabalho.

O grupo E é constituído por resoluções que se caracterizam por regulamentar aspectos não técnicos da atividade médica, tais como pesquisa em humanos, emissão de atestados, transfusão de sangue em Testemunhas de Jeová, autorização para necrópsias etc. Entendemos ser um grupo muito importante porque, diferentemente do grupo $C$ (cujas normas, não fosse pela característica exclusiva, poderiam ser incluídas neste grupo E), define de modo claro (a maior parte delas, pelo menos) formas de proceder relativas à matéria objetiva, algumas, inclusive, como o caso das Resoluções ns. $813 / 77$ e 1.331/89, integradas por características que as identificam com o padrão de normas de defesa do consumidor, conformando-se, de modo antecipatório, ao espírito da Lei n. 8.078/90. Por tratarem algumas de assuntos polêmicos, com implicações legais, orientam efetivamente os 
profissionais e criam condições para que, agindo segundo seus ditames, evitem ou diminuam a conflituosidade jurídica. Por outro lado, nada impede que o próprio Poder Judiciário delas se utilize para dirimir conflitos quando nenhuma outra norma houver (com força maior do que as Resoluções) que regulamente o mesmo objeto.

À semelhança do grupo anterior, o grupo $\mathrm{F}$ caracteriza-se por regulamentar aspectos objetivos da atividade médica, mas aqui tomando como objeto matéria de natureza técnica em sentido estrito. Cabem a este grupo as mesmas observações feitas com relação ao grupo anterior, referentes à utilidade para evitar ou dirimir conflitos jurídicos e à utilidade para tomada de decisões. Já nesse sentido, entretanto, possuem uma característica que as diferencia daquele grupo, uma vez que na matéria por elas tratada é muito mais vigorosa a característica de esclarecimento de aspectos dos direitos da população assistida, ressaltando-se, conseqüentemente, neste grupo, o elemento de direcionamento direto do benefício ao usuário.

A análise individual um pouco mais detalhada deste grupo de resoluções permitiu-nos dividi-las em três subgrupos, segundo consta da referida tabela.

Podemos indicar como paradigmas do primeiro subgrupo a Resolução n. 1.243 que estabelece critérios de eleição e proibição para tratamento com EDTA; a Resolução n. 1.457, referente a tratamento com oxigênio hiperbárico; a Resolução n. 1.477, que proíbe certa associação de medicamentos no tratamento da obesidade; e a Resolução n. 1.486, que veda o uso de determinadas associações de antibióticos e orienta quanto a outros. Merece também ser destacada a Norma n. 1.552, relativa ao uso de antibióticos. Esta resolução, a nosso ver, dirime qualquer dúvida sobre a liceidade ética do controle institucionalizado de condutas médicas, ao autorizar as Comissões de Controle de Infecção Hospitalar $(\mathrm{CCIH})$ a estabelecer protocolos para uso de antibióticos e controlar sua liberação. Embora, em si, não traga nenhum dispositivo técnico, esta característica está implícita nos termos dos artigos, especialmente na instituição do controle por parte da $\mathrm{CCIH}$ mediante protocolos. Alguns países europeus, temos notícias especialmente da Espanha e França, regulam de modo muito mais rígido condutas médicas, pelo menos em determinados campos de alta complexidade, como o dos transplantes de órgãos; as normas deste subgrupo F1 tendem, num certo sentido, a este propósito.

As normas do subgrupo F2 caracterizam-se por estabelecer parâmetros de recursos materiais e humanos. Citaremos como exemplo a Resolução n. 1.355, relativa a aspectos ligados à anestesia e ao uso de gases anestésicos, e a Resolução $n$. 1.451, que estabelece configurações materiais e de recursos humanos de unidades de pronto socorro. As normas 
deste subgrupo têm em comum o fato de permitirem, à diferença das demais, que órgãos fiscalizadores possam se valer delas para, de antemão, corrigir situações anômalas sem que necessariamente tenham de ser provocados pela ocorrência de fato ilícito. Essa fiscalização, por sua vez, poderá ser exercida não apenas pelos Conselhos de Medicina, como também por órgãos da Administração Direta ou mesmo pelo Ministério Público. A esse propósito, notícias dos meios de comunicação, em janeiro de 2000, davam conta de que o Ministério Público, baseado em norma emitida pelo CFM, protocolara ação contra a Prefeitura do Município de São Paulo, com vistas a corrigir problemas constatados em pronto socorro municipal. Salvo erro ou engano, trata-se exatamente da Resolução n. 1.451/95. Embora se revistam de aspectos especiais para este subgrupo, essas características não são estranhas ao subgrupo anterior. De observar, apenas, que neste segundo subgrupo não podemos negar a existência de certo grau de competência concorrente entre o Conselho Federal de Medicina e órgãos normatizadores da Administração. Por outro lado, esta caraterística torna o subconjunto especialmente vocacionado a servir de instrumento de políticas de efetivação de direitos nos termos propostos no presente texto.

As resoluções constantes do terceiro subgrupo têm dispositivos que se apresentam como princípios a serem observados e, a rigor, não são propriamente de natureza técnica. São três, entretanto, os motivos pelos quais as enquadramos neste grupo: 1. são constituídas por prescrições cujos benefícios se dirigem diretamente aos usuários; 2 . embora de natureza não técnica, têm como objeto aspectos dizentes diretamente a procedimentos (poderiamos dizer que são normas não técnicas sobre formas de procedimentos médicos técnicos e não técnicos); 3. a partir de princípios por elas estabelecidos, podem ser editadas normas técnicas no sentido dos subgrupos F1 e F2; esta última vocação, aliás, é característica de normas principiológicas. Citamos como exemplo os itens 2 do Princípio 13 e 1 do Princípio 14 do Anexo da Resolução n. 1.407, como dispositivos que se amoldam ao subtipo F2; normas com as características deste subgrupo F3 poderiam ser elaboradas, por exemplo, para aprimorar a aplicabilidade do item 14 do Princípio 11 (critério e composição de corpo de profissionais externos para avaliar o consentimento informado em psicocirurgia) ou ainda do Princípio 17 (Corpo de Revisão para os termos do item 2 do Princípio 16) (todos da Resolução n. 1.407), para ficarmos apenas nestes exemplos.

O grupo G, como já referido, é constituído por um conjunto de normas administrativas, mas com uma característica própria que as diferencia das resoluções do grupo $A$, constituída por se tratar de normas que de alguma forma se reportam diretamente aos mecanismos de fiscalização do exercício profissional. Os modos como cumprem essa função permitem classificá-las em subgrupos, de interesse para a análise, uma vez 
que demonstram os elementos pertinentes ao tema e que orientarão a discussão a seguir.

Restou inclassificada, com referência aos subgrupos, a Resolução $n$. $608 / 74$, pela qual o Conselho Federal de Medicina veda o uso, pelos ConseIhos Regionais, de qualquer Código de Ética que não seja o Código oficial então vigente. A eficácia desta norma decorre diretamente do poder vinculante da Lei n. 3.268/57 e, rigorosamente, ela não precisaria sequer ter sido editada. Daí o porquê de tal norma não se prestar, ao nosso ver, à análise que ora procedemos.

Com efeito, não há dúvidas quanto ao fundamento legal para o exercício fiscalizador profissional da pessoa do médico, instituído de forma clara e explícita pela Lei n. 3.268/57 e seu decreto regulamentador (Decreto n. 44.045/58), sendo esta, aliás, a grande razão de ser da própria lei, não havendo maiores dificuldades quanto aos procedimentos administrativos e processuais para a fiscalização da pessoa do médico. Já a fiscalização das organizações de saúde apresenta alguns problemas que transparecem dos dispositivos deste grupo. Vejamos preliminar e sucintamente os fundamentos legais do poder fiscalizador dos Conselhos sobre as organizações de saúde.

A Lei n. 6.839/1980 e a Lei n. 6.994/82 e seu Decreto regulamentador, n. 88.147/83, estabelecem a obrigatoriedade do registro das organizações e seus profissionais legalmente habilitados nos Conselhos, bem como dos tributos devidos. Nada expressam, entretanto, com relação ao poder fiscalizador e punitivo. As Resoluções em que tal poder é evocado (Resoluções ns. $1.089,1.215,1.342$ e 1.493) fazem-no todas com fundamento no caput do art. 12 do anexo do Decreto n. 44.045/58, regulamentador da Lei $n$. 3.258/57 e cujo texto, por oportuno, transcrevemos (a Resolução n. 1.342 também evoca a Lei $n$. 6.839/80, mas sem nenhum fundamento, segundo nosso entendimento):

"Art. 12. Recebida a queixa ou denúncia, o Presidente a encaminhará a uma Comissão de Instrução, que ordenará as providências especiais para o caso e, depois de serem elas executadas, determinará, então, a intimação do médico ou da pessoa jurídica denunciados para, no prazo de trinta dias a contar da data do recebimento dessa intimação, oferecer a defesa que tiver, acompanhando-a das alegações e dos documentos que julgar convenientes" (grifo nosso).

$\mathrm{Na}$ legislação pertinente, este é o único dispositivo a tratar do poder fiscalizador sobre pessoas jurídicas, mencionando a possibilidade de intimá-las, não havendo, entretanto, nenhuma referência a qualquer poder ou mecanismo sancionatório. Aparentemente, essa circunstância não seria óbice à ação fiscalizadora porque há a possibilidade de que as sanções 
sejam aplicadas à pessoa do Diretor Técnico(1) e com efeito assim o determinam de forma expressa as Resoluções ns. 687, 788, 997, 1.342 e 1.401 e de forma implícita as Resoluções ns. 1.214 e 1.493, que constituem o primeiro subgrupo. Essa estratégia, por sua vez, é viabilizada por dispositivos legais que exigem a presença de um Diretor Técnico com formação médica em todos os estabelecimentos hospitalares ou de assistência médica (art. 28 do Decreto n. 20.931, de 11 de janeiro de 1932, e art. 15 da Lei n. 3.999, de 15 de dezembro de 1961), mas não se mostra de todo eficaz, segundo nosso entendimento, aspecto a que voltaremos oportunamente.

A obrigatoriedade de registro e cadastramento de empresas é estabelecido nas resoluções do segundo subgrupo.

O terceiro subgrupo é constituído por normas que organizam a atividade fiscalizadora em sentido estrito. Este subconjunto carecerá ou não de maior eficácia em função da qualidade do modelo de fiscalização como um todo, sobretudo de definições mais claras dos poderes dos Conselhos sobre todos os tipos de organizações e empresas, objeto do subconjunto anteriormente estudado.

O quarto subgrupo caracteriza-se por conter prescrições de condutas cujos destinatários são empresas e instituições prestadoras de serviços de saúde. No total, são cinco as hipóteses reguladas por essas duas resoluções do Conselho Federal de Medicina, mediante dispositivos que, implicam comandos dirigidos diretamente às pessoas jurídicas. De registrar que, nas hipóteses da Resolução n. 997, a punição se faz na pessoa do Diretor Técnico, enquanto para a Resolução n. 1.401, esta se faz na pessoa do Diretor Técnico e da própria instituição, como se verá ao estudarmos o grupo seguinte.

Finalmente, com relação à cominação de pena à pessoa jurídica, o cancelamento do registro é admitido abstrata e genericamente como forma de punição a instituições nos arts. 17 a 19, constituintes do capítulo IV da Resolução $n$. 1.214, e estatuído de forma expressa no art. 6 da Resolução n. 1.401, se verificada a incidência de alguma das hipóteses desta norma, sendo esta a única resolução que alberga uma hipótese concreta de punição para os entes jurídicos. Há, portanto, nítido predomínio do número de resoluções que prescrevem punição à figura do Diretor Técnico, em contraposição àquelas que prescrevem punição diretamente à pessoa jurídica.

Analisando-se agora o conjunto de características dos subgrupos, podemos fazer uma idéia global do Grupo $G$ e dos problemas que se apresentam no que se refere à extensão da normação e fiscalização às pessoas

(1) Usaremos exclusivamente o termo Diretor Técnico para nos referirmos indiferentemente a esta figura e à figura do Diretor Clínico. 
jurídicas, empresas prestadoras de serviços de saúde. Verificamos que os subgrupos 2 e 3, em contraposição aos demais, são constituídos por normas essencialmente organizacionais, cuja eficácia dependerá em grande parte, se não no todo, da eficácia das normas dos demais subgrupos. 0 mesmo se pode dizer das resoluções constituintes do subgrupo 4 . Com relação a estes últimos, parece-nos claro que a ínfima quantidade de dispositivos regulando condutas das instituições é conseqüência da inexistência de um modelo nítido e forte de normação e de fiscalização/punição sobre esses entes e esta constatação remete-nos finalmente para os subgrupos 1 e 5, que regulam exatamente as formas de punição. Já fizemos notar que, das duas formas possiveis de responsabilização e punição, predomina aquela que se faz na figura do Diretor Técnico. Já manifestamos nossa opinião de que o modelo de punição baseado na figura do Diretor Técnico é sob certos aspectos pouco eficaz.

Expliquemo-nos agora. Este convencimento advém de nossa experiência pessoal e fundamenta-se no conhecimento que possuímos do modo de estruturação e funcionamento dos mecanismos de decisão e poder dentro das organizações de saúde. De modo geral, o Diretor Técnico não tem meios materiais de controlar todos os elementos a que a rigor seria obrigado para o fiel cumprimento da seu munus, uma vez que toda a máquina burocrática da instituição, com raras exceções, está nas mãos de diretorias leigas que não são afetadas por processos ético-profis-sionais. Essa circunstância é verificada em todos os tipos de organizações, seja na mais simples organização filantrópica numa pequena cidade do interior, seja, de forma ainda mais dramática, numa grande empresa interme-diadora de assistência médica. É por esta ordem de idéias que julgamos de suma importância que seja estabelecido um modelo bem definido e forte de fiscalização sobre as pessoas jurídicas prestadoras de serviços de saúde, cumprindo garantir, como primeiro passo, substrato legal mais consistente do que $o$ atualmente existente e, como segundo passo, um modelo sancionatório explícito, com multas, por exemplo, no lugar de cancelamento do registro, atitude esta que nos parece drástica demais e por isso pouco aplicável. Esse mesmo modelo definiria melhor, também, hipóteses de imputação de responsabilidade ao Diretor Técnico, exclusiva ou associadamente à punição da instituição.

Importa registrar, ao terminar a análise deste grupo de resoluções, que nos parece que aqui não se aplicam os critérios de eficácia propostos para a discussão neste texto. Antes, a eficácia para este conjunto de normas traduzir-se-á na consecução de um sistema normativo que permita, por intermédio de fiscalização eficiente, aplicar as demais resoluções.

Em relação à distribuição, tomamos o ano de 1984 como referência por dois motivos, sobre os quais já nos reportamos na Introdução: 1. à mercê do momento político vivido pelo Brasil à época, houve substituição no comando dos órgãos representativos de classe, na área da saúde, de ele- 
mentos conservadores por elementos progressistas; 2. o país vivia então um clima político pré-constituinte e as propostas para a área social e política da Constituição de 1988 já estavam delineadas por essa época. Notamos que a produção normativa foi bem maior no segundo período: 78 Resoluções, incluída a de n. 1.246/88 (Código de Ética Médica), correspondendo a $73 \%$. Esse comportamento não se deu de modo igual para todos os grupos, havendo alguns dados interessantes: 1 . os grupos $\mathrm{B}$ e $\mathrm{C}$ restringem-se praticamente ao primeiro período; 2. o grupo $\mathrm{F}$ restringe-se exclusivamente ao segundo período; 3 . esta análise superficial aparentemente confirma a gradativa mudança na postura da instituição, que substituiu ao longo do tempo a edição de normas do tipo B e $C$ por normas do tipo $F$. Uma análise mais detalhada da qualidade das normas do grupo $G$ seria necessária e talvez interessante para corroborar este raciocínio.

Retomando brevemente a discussão metodológico-epistemológica que iniciáramos na Introdução, cumpre registrar, sem maiores aprofundamentos, e valendo-nos mais uma vez dos conceitos de Moles, que a classificação que ora acabamos de expor, embora não exaustiva, não se aplicou a apenas uma resolução, o que pode ser considerado "um resíduo negligenciável do conjunto de dados"(12); não se mostrando de todo específica, uma vez que há resoluções que eventualmente se enquadrariam em mais de um grupo. Nesses casos, o primeiro critério para alocação no grupo foi o do dispositivo contido na norma que lhe atribuísse a condição de eficácia e o segundo, aquele em que se enquadrasse a maior parte dos dispositivos normativos "eficazes" da resolução. Pelo mesmo motivo podemos atribuir-lhe certo grau de ambigüidade e considerá-la apenas parcialmente dicotomizante. Quanto à simplicidade operacional, entendemos que apenas a eventual utilização futura da classificação ora proposta permitirá avaliar, podendo-se dizer o mesmo no que diz respeito à validade da classificação como um todo, em face da incidência das limitações acima registradas, no que tange aos critérios de avaliação de Moles.

\section{CONCLUSÃO}

A análise a que submetemos o conjunto de 106 Resoluções Normativas do CFM mostrou a presença de sete grupos de normas, das quais dois grupos (E e F) satisfazem os critérios propostos inicialmente como garantidores de eficácia em tese e um terceiro $(G)$ mostrou ser um grupo especial, cujos critérios de eficácia se mostraram, à primeira vista, diferentes, merecendo análise ulterior.

A importância da análise a que nos propusemos advém do fato de que, entendidos os mecanismos de eficácia das normas estudadas, a edi- 
ção continuada de resoluções segundo diretrizes previamente traçadas e com finalidades definidas se afeiçoará à natureza finalística do direito sanitário, aduzida das vantagens de se tratar de um ente normador não adstrito às formalidades do processo legislativo e mais conforme aos ditames da sociedade civil, fatores que podem compensar sua inaptidão para legislar e a conseqüente limitação de competência normativa.

Assim admitido, podemos dizer que o poder fiscalizador e as Resoluções Normativas do CFM podem atuar como importante instrumento a coadjuvar as políticas públicas de saúde, por meio, fundamentalmente, de dois mecanismos integrados: 1. produzindo normas que limitam e coordenam a prática médica e simultaneamente balizam para o usuário seus direitos em pontos específicos, produzindo instrumentos legais que podem ser usados na restauração do direito violado nos casos de dano. Este, entretanto, não seria o único resultado concreto a obter mediante a prática de edição desse tipo de norma. Entendemos que essa produção normativa deveria ser sistematizada e seguir diretrizes previamente definidas, a partir de estudos que identificassem grandes áreas ou conjuntos de situações cuja regulação viesse a produzir efeitos concretos no exercício da Medicina, do ponto de vista da qualidade do serviço prestado ao usuário. Essa atividade abrangeria um número apreciável de condutas médicas, aumentando as opções para uso individual das normas como instrumento técnico-jurídico no exercício do direito de ação, mas, principalmente, direcionando de forma mais ativa possivel a atividade médica em campos polêmicos com relação aos direitos e benefícios ao consumidor; 2 . um conjunto relativamente grande e estruturado, segundo diretrizes previamente estabelecidas, de normas com essas características potencializaria o efeito fiscalizador dos Conselhos, permitindo que o maior número possível de condutas eventualmente lesivas ao usuário fossem identificadas e ações preventivas pudessem ser levadas a efeito com muito mais freqüência e eficiência, antecipando-se e diminuindo a incidência do dano. Normas do subgrupo F2 poderiam ser utilizadas diretamente por instituições outras que não exclusivamente os Conselhos, a exemplo do Ministério Público, segundo já tivemos a oportunidade de citar com referência à Resolução n. 1.451.

O pleno efeito dessa normação sistematizada e orientada por diretrizes previamente definidas, entretanto, só será obtido se houver um sistema fiscalizador ativo e com condições materiais e legais de agir. Cumpre, portanto, definir, mediante lei, um modelo em que fiquem claras as competências dos Conselhos com relação às pessoas jurídicas prestadoras de serviço médico-hospitalar à população.

Admitida a correção das hipóteses acima, mediante uma atividade normadora planejada, teleologicamente informada, com metas pré-definidas, atividade esta que integre a função promocional do Direito, entendido 
este termo no sentido que Ihe atribui Tojal(17), o Conselho Federal de Medicina poderá eventualmente promover significativas mudanças na qualidade da atenção à saúde prestada à população. É impossível, nesse momento, divisar as proporções ou o rumo que esta atividade poderia tomar se fosse encetada desta forma. Talvez alguns paradigmas já estejam sendo rompidos; indícios seriam a moderada mudança no perfil qualitativo das normas editadas, segundo expusemos, e, sobretudo, o padrão da Resolução $n$. 1.552, que rompe, com arraigada tradição de auto-suficiência e inviolabilidade do médico na condução do tratamento.

Finalizando, reiteramos que a utilidade da classificação alcançada neste texto poderá ser avaliada mediante sua aplicação em outros modelos metodológicos e com uso de critérios paralelos que possam testemunhar sua pertinência. É intenção do autor aplicá-la em avaliação sistemática do papel destas normas na formação da convicção do juiz em matéria de direito sanitário.

\section{BIBLIOGRAFIA}

1. BOBBIO, N. Teoria della Norma Juridica. Torino, G. Giappichelli, 1958, cap. II.

2. Idem, Ibidem, cap. III.

3. CAMPANA, A. O. "O Método Científico". In CAMPANA, A. O. Investigação Científica na Área Médica. São Paulo, Manole, 2001, cap. IV, pp. 51/63.

4. CAMPINLONGO, C. F. "Os Desafios do Judiciário: Um Enquadramento Teórico". In FARIA, J. E. (org.). Direitos Humanos, Direitos Sociais e Justiça. São Paulo, Malheiros Editores, 1994, cap. 2, pp. 30/51.

5. CAMPINLONGO, C. F. "O Trabalhador e o Direito à Saúde: A Eficácia dos Direitos Sociais e o Discurso Neoliberal". In GIORGI, B. Di; CAMPINLONGO, C. F.; PIOVESAN, F. Direito, Cidadania e Justiça. São Paulo, Revista dos Tribunais, 1995, pp. 125/140.

6. DALLARI, S. G. "O Direito à Saúde”. Revista Saúde Pública. São Paulo, 22 (1): $57-63,1988$.

7. DALLARI, S. G. "O papel do município no desenvolvimento de políticas de saúde". Revista Saúde Pública. São Paulo, 25 (5), 1991, pp. 401/405.

8. DINAMARCO, C. R. A Instrumentalidade do Processo. São Paulo, Revista dos Tribunais, 1987, pp. 13/24. 
9. GORDILlO, A. Princípios Gerais do Direito Público. São Paulo, Revista dos Tribunais, 1977, cap. II, pp. $27 / 48$.

10. LOPES, J. R. L. "Direito Subjetivo e Direitos Sociais: O Dilema do Judiciário no Estado Social de Direito". In FARIA, J. E. (org.). Direitos Humanos, Direitos Sociais e Justiça. São Paulo, Malheiros Editores, 1994, cap. 7, pp. $113 / 143$.

11. MELLO, C. A. B. Natureza e Regime Jurídico das Autarquias. São Paulo, Revista dos Tribunais, 1968, cap. III, pp. 24/127.

12. MOLES, A. A. A Criação Científica. São Paulo, Perspectiva, 1981, cap. 6 , pp. $129 / 160$.

13. PIETRO, M. S. Z. Di. Direito Administrativo. $6^{\mathrm{a}}$ ed. São Paulo, Atlas, 1996, p. 74.

14. Idem, ibidem, p. 313.

15. PUTNAMI, R. O. Making Democracy Work - Civic Traditions in Modern Italy. Princeton, Princeton University Press, 1993, cap. 4, pp. 82/120.

16. REALE, M. Lições Preliminares de Direito. 11ª ed., São Paulo, Saraiva, 1984 , cap. X.

17. TOJAL, S. B. B. Teoria Geral do Estado - Elementos de uma Nova Ciência Social. Rio de Janeiro, Forense, 1977.

18. TOJAL, S. B. B. "Constituição Dirigente de 1988 e o Direito à Saúde". In MORAES, A. Os 100 Anos da Constituição Federal. São Paulo, Atlas, 1999, pp. 33/44. 


\section{TABELA 1-DISTRIBUIÇÃO DOS GRUPOS SEGUNDO OS CRITÉRIOS DE CLASSIFICAÇÃO - QUADRO SINÓPTICO}

\begin{tabular}{cccccl}
\hline GR & $1^{\circ}$ CRT & $2^{\circ}$ CRT & $3^{\circ}$ CRT & $4^{2}$ CRT & $\begin{array}{c}\text { CARACTERístiCA } \\
\text { EXCLUSIVA }\end{array}$ \\
A & + & - & - & - & Não \\
B & - & + & - & - & Profissão Liberal \\
C & - & + & - & - & Prescrições Genéricas \\
D & - & + & - & - & Ato Privativo de Médico \\
E & - & + & - & - & Não \\
F & - & - & + & - & Não \\
G & - & - & - & + & Não \\
\hline
\end{tabular}

$\therefore$ A característica não se aplica ao grupo.

+: A característica aplica-se ao grupo.

1 Critério: normas "meramente" administrativas.

$2^{\circ}$ Critério: normas prescritivas; matéria regulada é de natureza não técnica.

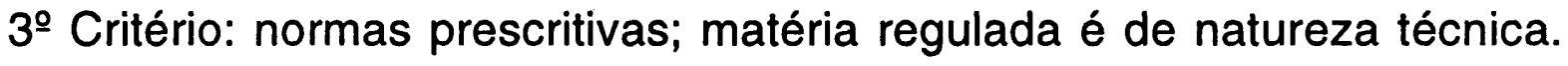

4 Critério: normas organizacionais do sistema de fiscalização. 
GRÁFICO 1 - DISTRIBUIÇÃO TEMPORAL E POR GRUPOS DAS RESOLUÇÕES NORMATIVAS

\begin{tabular}{|c|c|c|c|c|c|c|c|}
\hline & B & C & D & $E$ & $\mathbf{F}$ & $\mathbf{G}$ & $\begin{array}{c}\text { Não } \\
\text { Classificado }\end{array}$ \\
\hline 1965 & * & & & & & & \\
\hline \multicolumn{8}{|l|}{1955} \\
\hline 1967 & ${ }^{\star}$ & & & & & & \\
\hline \multicolumn{8}{|l|}{1968} \\
\hline \multicolumn{8}{|l|}{1969} \\
\hline \multicolumn{8}{|l|}{1970} \\
\hline \multicolumn{8}{|l|}{1971} \\
\hline 1972 & & * & & & & & \\
\hline 1973 & & & & & & * & \\
\hline 1974 & & & & & & * & \\
\hline 1975 & & $\star \star \star$ & & $\star$ & & * & \\
\hline \multicolumn{8}{|l|}{1976} \\
\hline 1977 & $\star$ & & & $\star$ & & ${ }^{\star}$ & \\
\hline 1978 & ${ }^{*}$ & & & & & & \\
\hline 1979 & & * & & * & & & \\
\hline 1980 & & & & $\star \star \star \star$ & & $\star$ & \\
\hline 1981 & & & & * & & & \\
\hline 1982 & * & & & * & & & \\
\hline \multicolumn{8}{|l|}{1983} \\
\hline \multicolumn{8}{|l|}{1984} \\
\hline 1985 & & & & & & $\star \star$ & \\
\hline 1986 & $\star$ & & & & & & \\
\hline 1987 & & & & & * & & \\
\hline 1988 & & & & & & & $\star$ \\
\hline 1989 & & & & $\star \star$ & & & \\
\hline 1990 & & & & & & $\star$ & \\
\hline 1991 & & & & & & ${ }^{\star}$ & \\
\hline 1992 & & & $\star$ & & $\star \star \star \star$ & ${ }^{*}$ & \\
\hline 1993 & & & & & * & & \\
\hline 1994 & & & & $\star$ & $\star \star \star \star$ & & \\
\hline 1995 & & & & & $\star \star \star \star \star$ & & \\
\hline 1996 & & & & $\star$ & & & \\
\hline 1997 & & & ** & $\star \star \star$ & 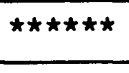 & ${ }^{*}$ & \\
\hline 1998 & & $\star$ & & & $\star \star \star \star$ & ${ }^{*}$ & \\
\hline 1999 & & & $\star$ & 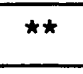 & * & ${ }^{*}$ & \\
\hline
\end{tabular}

